\title{
Isolation and Characterization of a Chinese
} Hamster Ovary Heparan Sulfate Cell Mutant Defective in Both Met Receptor Binding and Hepatocyte Growth Factor NK1/Met Signaling

\author{
Tong CaO Jing Pan ${ }^{\mathrm{b}}$ Xiulian Li $\mathrm{i}^{\mathrm{a}, \mathrm{c}}$ Yanli He $\mathrm{H}^{\mathrm{a}, \mathrm{c}}$ Yifei Jiang ${ }^{\mathrm{a}, \mathrm{c}}$ Yajing Chang ${ }^{\mathrm{a}, \mathrm{c}}$ \\ Qi Zhang ${ }^{b}$ Ying Lan ${ }^{c}$ Hua Wang ${ }^{a}$ Wenjie Jiao ${ }^{a}$ Zibin Tian ${ }^{a}$ Lijuan Zhang ${ }^{a}$ \\ ${ }^{a}$ Affiliated Hospital of Qingdao University, Qingdao, China, ${ }^{b}$ Cancer Center, Medical College of \\ Wisconsin, Milwaukee, USA, 'School of Medicine and Pharmacy, Ocean University of China, Qingdao, \\ China
}

\section{Key Words}

Heparan sulfate - Hepatocyte growth factor (HGF) - Met receptor - NK1 domain of HGF • Chinese hamster ovary $(\mathrm{CHO})$ cells

\begin{abstract}
Background/Aims: The up-regulation of hepatocyte growth factor/receptor, HGF/Met, signal transduction is observed in most of human cancers. Specific heparan sulfate structures enhance the HGF/Met signaling at both cell and animal-based model systems. Biochemical studies indicate that heparan sulfate interacts with $\mathrm{HGF}$ and a natural occurring splicing variant NK1 of HGF with similar affinity. However, it is currently unknown if cell surface heparan sulfate binds to Met at physiological conditions and if specific cell surface heparan sulfate structures are required for effective HGF/Met or NK1/Met signaling. Methods: An established flow sorting strategy was used to isolate a soluble Met recombinant protein-binding positive or negative $\mathrm{CHO}$ cell clones different only in specific heparan sulfate structures. The cell surface bindings were imaged by confocal microscopy and flow cytometry analysis. Glucosamine vs. galactosamine contents from media-, cell surface-, and cell association glycosaminoglycans were quantified by HPLC. ${ }^{35} \mathrm{~S}$-sulfate labeled glycosaminoglycans were characterized by anion exchange and size-exclusion HPLC. Heparan sulfate disaccharide compositions were determined by HPLC-MS analysis. Western blot analyses of MAPK-p42/44 were used to monitor HGF- and NK1-facillated Met signaling. Results: CHO-Positive but not CHO-Negative cell surface heparan sulfate bound to Met recombinant protein and HGF/NK1 further promoted the binding. Overall glycosaminoglycan analysis results indicated that the $\mathrm{CHO}$-Negative

T. Cao and J. Pan contributed equally to this work.

Lijuan Zhang

Affiliated Hospital of Qingdao University

Qingdao, 266003 (China)

Tel. +86 0532-82031615, E-Mail zhanglj@qduhospital.cn
\end{abstract}




\section{Cellular Physiology Cell Physiol Biochem 2018;48:1480-1491 \\ \begin{tabular}{l|l} 
DOI: 10.1159/000492258 & a 2018 The Author(s). Published by S. Karger AG, Basel \\
www.karger.com/cpb
\end{tabular} \\ Cao et al.: a Heparan Sulfate Cell Mutant Defective in Hepatocyte Growth Factor NK1/ \\ Met Receptor Signaling}

cells had reduced amount of heparan sulfate, shorter chain length, and less 6-O-sulfated disaccharides compared to that of $\mathrm{CHO}$-Positive cells. Moreover, $\mathrm{CHO}-\mathrm{Negative}$ cells were defective in NK1/Met but not HGF/Met signaling. Conclusions: This study demonstrated that soluble Met recombinant protein bound to cell surface HS at physiological conditions and a Met /HGF or NK1/HS ternary signaling complex might be involved in Met signaling. Shorter HS chains and reduced 6-O-sulfation might be responsible for reduced Met binding and the diminished NK1-initiated signaling in the $\mathrm{CHO}$-Negative cells. The unique $\mathrm{CHO}$-Positive and $\mathrm{CHO}-$ Negative cell clones established in current study should be effective tools for studying the role of specific glycosaminoglycan structures in regulating Met signaling. Such knowledge should be useful in developing glycosaminoglycan-based compounds that target HGF/Met signaling.

\section{Introduction}

The up-regulation of HGF (hepatocyte growth factor)/Met (proto-oncogenic c-met receptor) signal transduction is observed in a variety of human cancers [1-6] where Met plays a central role in signaling pathways that regulate cancer cell proliferation, epithelialmesenchymal transition, cell migration, and tumor invasion. Effective targeting HGF/Metpathway for cancer treatment has been conducted with over 100 clinical trials and striking results have not been achieved so far [7, 8]. Specific heparan sulfate (HS) structures enhance Met signaling at both cellular [9-11] and animal-based model systems [12]. Defects in secondary and ductal side-branching are observed in mice of targeted conditional deletion of c-Met in mammary epithelial cells. In consistent, targeted conditional deletion of the genes responsible for HS biosynthesis in mice shows defects not only in secondary branching and ductal side-branching but also in primary ductal branching, terminal end bud bifurcation, and lobuloalveolar formation. The reason behind the severe defects observed in the mouse model is that HS also participates in regulating many growth factor signaling pathways not limited to fibroblast growth factors (FGFs)/FGFRs, vascular endothelial growth factors (VEGFs)/VEGFRs, glial cell line-derived neurotrophic factor (GDNF)/c-Ret/GFRa1, B-cell activating factor (BAFF)/ transmembrane activator and CAML interactor (TACI), platelet derived growth factor (PDGF)/PDGFR, Indian hedgehog (Ihh), bone morphogenetic proteins (BMP), and Wnt signaling pathways [13]. Therefore, it is important to understand the roles of HS played in regulating the HGF/Met signaling pathway in a more defined cellular system.

Glycosaminoglycans (GAGs) are linear polysaccharides produced by all animal cells in the form of proteoglycans. Two major types of sulfated GAGs are HS and chondroitin sulfate (CS). GAGs line the cell surface, fill the extracellular space. The biological functions of GAGs especially HS rely on their ability to bind to hundreds of molecules including extracellular matrix proteins, proteases, protease inhibitors, growth factors, growth factor receptors, chemokines, and interleukins [13]. Of increasing interest is the direct binding between HS and tyrosine kinase receptors, such as FGFRs [14], and the presence of growth factor/growth

Fig. 1. Domain structures of HGF, NK1, Met, and Met-Fc. A. HGF. HGF consists of $\mathrm{N}$-terminal domain $(\mathrm{N})$, four Kringle domains $(\mathrm{K} 1, \mathrm{~K} 2, \mathrm{~K} 3$, and $\mathrm{K} 4)$, and a serine proteinase-like domain that has no detectable protease activity (SP); B. NK1; NK1 consists of only N and K1 domains, C. Met. The extracellular domain of Met contains a semaphorin homology region (Sema); a cysteinerich region (Psi); and four immunoglobulin-like repeats (Iglike). The intracellular domain contains juxtamembrane (JM), tyrosine kinase (TK) and carboxyl terminal (CT) domains,

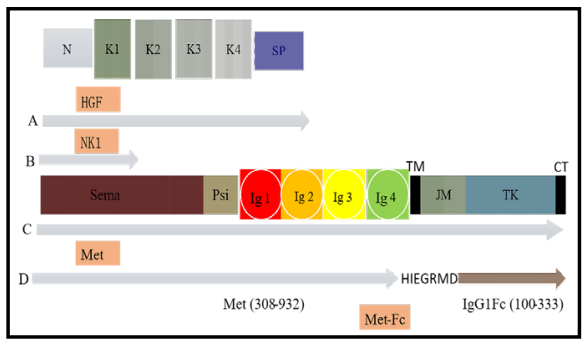
where transmembrane domain TM separates the two extra- and intracellular domains; D. Met-Fc. It is a soluble protein containing Met (Ser308-Thr932), a peptide linker (HIEGRMD) and -human Fc domain of IgG1 (Pro100-Lys333) that can be recognized by florescence-labeled protein A.

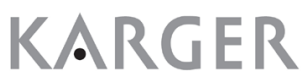




\section{Cellular Physiology Cell Physiol Biochem 2018;48:1480-1491 \\ and Biochemistry Published online: July 31, $2018 \quad \begin{aligned} & \text { DOI: 10.1159/000492258 } 2018 \text { The Author(s). Published by S. Karger AG, Basel } \\ & \text { www.karger.com/cpb }\end{aligned}$ \\ Cao et al.: a Heparan Sulfate Cell Mutant Defective in Hepatocyte Growth Factor NK1/ \\ Met Receptor Signaling}

factor receptor/HS ternary complex [15-17].

The HS binding domains in HGF and NK1 (the N- and K1 domain of HGF) have been identified [10,11,18-20], Met also interacts with heparin with a lower affinity compared to HGF[21]. Although biochemical studies indicate the formation of HGF/heparin/Met ternary complex, but it is unknown if Met resembles FGFRs in that it also binds HS at cell surface. To understand the molecular basis, the domain structures for HGF, NK1, Met, and Met-Fc fusion protein used in current study are summarized in Fig. 1. HGF consists of $\mathrm{N}$-terminal domain $(\mathrm{N})$, four Kringle domains (K1, K2, K3, and $\mathrm{K} 4)$, and a serine proteinaselike domain that has no detectable protease activity (SP). NK1 consists of only N and K1 domains. Based on the published reports, both $\mathrm{N}$ and $\mathrm{K} 1$ domains are involved in HS binding [18-20]. Met (mesenchymal-epithelial transition factor) is a proto-oncogene that encodes the protein Met, also known as c-Met or hepatocyte growth factor receptor (HGFR). HGF activation triggers transphosphorylation of the tyrosines Tyr 1234 and Tyr 1235, which engage various signal transducers, such as MAPK, PI3K, RAS, STAT, thus initiates a whole spectrum of signaling events called the invasive growth program. The extracellular domain of Met contains a semaphorin homology region (Sema); a cysteine-rich region (Psi); and four immunoglobulin-like repeats (Ig-like). The intracellular domain contains juxtamembrane (JM), tyrosine kinase (TK) and carboxyl terminal (CT) domains, where transmembrane domain TM separates the two extra- and intracellular domains. Met-Fc is a soluble protein containing Met (Ser308-Thr932), a peptide linker (HIEGRMD) and human Fc domain of IgG1 (Pro100-Lys333) that can be recognized by florescence-labeled protein A. Both Met and MetFc contain four immunoglobulin-like repeats. The immunoglobulin-like repeats in FGFRs are responsible for direct HS binding. Thus, we assumed that Met-Fc should bind to HS based on the published report [21].

GAG-defective mutant cell lines provide a powerful in vivo tool for studying the biosynthesis, structure, and function of GAGs under controlled cell cultural conditions [22-24]. To identify the specific HS structures that support Met binding and signaling, we generated both Met binding-negative and positive CHO mutant cell lines. We not only characterized the HS structures of the cell mutants but also demonstrated that soluble MetFc bound to cell surface HS at physiological conditions. Most importantly, our data revealed that a Met/HS/HGF or NK1 ternary signaling complex might be involved in Met signaling.

\section{Materials and Methods}

\section{Materials}

FGFR1beta(IIIc)/Fc, Met-Fc (human Met beta (Ser308-Thr932-HIEGRMD-Human IgG1 (Pro100Lys333) and HGF were purchased from R\&D Systems (Minneapolis, MN). Alexa Fluor 488 conjugated antihuman Fc was from Molecular Probes, Inc. (Eugene, OR). Human NK1 was a kind gift from Dr. Donald P. Bottaro of National Institutes of Health. The CHOK1 cell line was a generous gift of Dr. Jeffrey D. Esko of University of California, San Diego. Fetal bovine serum was from Sigma.

\section{Cell culture}

CHO-K1.5 cell clone that has three copies of 3-O-sulfotransferase genes is made from CHOK1 cells [25]. CHO-Neg and CHO-Pos cells were derived from CHO-K1.5 cells. All CHO cell lines were grown in Ham's F12 medium containing 10\% FBS, 100 units/ml penicillin G, and $100 \mu \mathrm{g} / \mathrm{ml}$ streptomycin sulfates. Cells were passaged with trypsin every 3-4 days and revived periodically from frozen stocks as described previously [25].

Cell surface binding assays for Met-FC \pm HGF or NK1

Adherent cells were removed from tissue culture plates after incubation with an EDTA solution ( $4 \mathrm{mM}$ EDTA plus $10 \%$ FBS in PBS). After wash with PBS, $5 \times 10^{5}$ cells were re-suspended in $50 \mu \mathrm{L}$ of FACS buffer (PBS with $10 \% \mathrm{FBS}$ ) incubated on ice for $30 \mathrm{~min}$ with $4 \mu \mathrm{M}$ of cMET-Fc $\pm 2 \mu \mathrm{M}$ of HGF. After washing once with $1 \mathrm{ml}$ of FACS buffer, $1 \mu \mathrm{L}$ of fluorescence-labeled anti-Fc antibody was added to the cells and incubated 


\section{Cellular Physiology Cell Physiol Biochem 2018;48:1480-1491

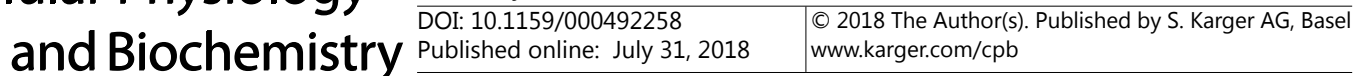 \\ Cao et al.: a Heparan Sulfate Cell Mutant Defective in Hepatocyte Growth Factor NK1/ Met Receptor Signaling}

on ice for another $30 \mathrm{~min}$, then wash three times with FACS buffer to remove nonspecific binding and free secondary antibody. Flow cytometry was performed with FACS can instrument (Becton Dickinson).

\section{Enzymatic digestion of GAGs from cell surfaces}

Cell suspensions were centrifuged at $500 \mathrm{xg}$ for $5 \mathrm{~min}$ and were re-suspended in PBS containing $0.1 \%$ BSA. Heparitinases I, II, III $(0.06 \mathrm{U} / \mathrm{mL}$ final concentration) or chondroitinase ABC $(0.1 \mathrm{U} / \mathrm{mL}$ final concentration) was added to a $50 \mu \mathrm{l}$ of cell suspension and incubated at $37^{\circ} \mathrm{C}$ in a shaking incubator for $2 \mathrm{~h}$. After three washes with cold PBS containing $0.1 \%$ BSA, the cells were incubated sequentially $4 \mu \mathrm{M}$ of METFc $\pm 2 \mu \mathrm{M}$ of HGF or NK1 and anti-Fc antibodies and analyzed by flow cytometry.

GAG isolation from cell cultured cells

GAG isolation from normally cultured cells is the same as described previously [25].

\section{GAG quantification}

The quantification method for glucosamine and galactosamine content in purified GAG samples has been described in detail previously [26].Briefly, the steps are acid hydrolysis, sodium borohydride reduction, precolumn derivatization with o-phthaldialdehyde (OPA) and 3-mercaptopropionic acid (3MPA), and reversed phase HPLC separation with fluorescence detection of the isoindole derivatives. GAG aliquots containing $6 \mathrm{nmol}$ of norleucine are used as an internal standard. Quantification of the GlcN and GalN peaks was based on calibration curves derived from 10 external standards ranging from 2.5 pmol to 1280 pmol $\left(y=2.085 x-22.59, r^{2}=0.997\right.$ for GlcN and $y=2.085 x-22.59, r^{2}=0.9958$ for GalN in current study).

${ }^{35} \mathrm{~S}$-sulfate radiolabeling of $\mathrm{CHO}$-Pos and $\mathrm{CHO}$-Neg cells and isolation of ${ }^{35} \mathrm{~S}$-sulfate labeled GAG chains

Cells were labeled at $37^{\circ} \mathrm{C}$ for $4 \mathrm{~h}$ with $100 \mu \mathrm{Ci} / \mathrm{ml} \mathrm{Na} 2^{35} \mathrm{SO} 4$ (25-40 Ci/mg, Amersham Corp.) prepared in sulfate-free growth medium as described preciously [27]. Isolation of ${ }^{35} \mathrm{~S}$-sulfate labeled GAG chains including protease digestion and $\beta$-elimination according to the publication [28]. ${ }^{35} \mathrm{~S}$-sulfate labeled HS was prepared from ${ }^{35} \mathrm{~S}$-sulfate labeled GAGs of both CHO-Pos and CHO-Neg cells after chondroitnase ABC (EC 4.2.2.4, purchased from Seikagaku) digestion according to the published protocol [24].

\section{Anion exchange or size exclusion HPLC analysis of ${ }^{35}$ S-sulfate labeled GAGs or HS}

${ }^{35} \mathrm{~S}$-sulfated labeled GAGs from both CHO-Pos and CHO-Neg cells were analyzed by anion-exchange high performance liquid chromatography (HPLC) (DEAE-3SW, $7.5 \mathrm{~mm} \times$ 7.5-cm column, TosoHaas, PA) using the published protocol [28]. The chain size distribution of ${ }^{35} \mathrm{~S}$-sulfate labeled HS from both CHO-Pos and CHO-Neg cells were compared by gel filtration chromatography (TSK G3000SW HPLC column, $60 \mathrm{~cm} \mathrm{x}$ $7.5 \mathrm{~mm}$, TosoHass, Inc.). Blue dextran and ${ }^{35} \mathrm{~S}$-sulfate were used to determine the $V$ o and $V t$ of the column. Radioactivity in the effluent was monitored with an in-line radiodetector (Radiomatic Flo one/beta, Packard Instruments) with sampling rates every $6 \mathrm{~s}$ and data averaged over $1 \mathrm{~min}$ were used to plot the elution profiles.

\section{Disaccharide compositional analysis of HS}

Heparitinase I, II, and III were purchased from Seikagaku. HS disaccharide standards were purchased from Sigma-Aldrich and Seikagaku. The disaccharide compositional analysis was conducted using the same GAGs used for GlcN and GalN quantification. The method is the same as we previously published one [26].

\section{Activation of the mitogen-activated protein (MAP) kinase pathway}

CHO-Neg and CHO-Pos cells were seeded at a confluent density into a 6-well plate in 2 ml of Ham's F-12, 10\% (v/v) FBS, and serum-starved overnight before treatment with HGF or NK1 (10 ng/mL each) for $10 \mathrm{~min}$. Cells were then lysed in $0.1 \mathrm{~mL}$ of non-reducing Laemmli SDS-sample buffer. After heating at $100^{\circ} \mathrm{C}$ for 3 minutes, equivalent amounts of protein samples were subjected to SDS-PAGE on a $10 \%$ acrylamide gel and then blotted onto nitrous cellular membrane. Blots were blocked for $1 \mathrm{~h}$ with $5 \%$ (w/v) non-fat dried milk in TBST, probed with a mouse monoclonal antibody against phosphor-p42/44 MAPK (1:1000, Cell Signal Tech, Inc) or p42/44 MAPK (1:1000, Cell Signal Tech, Inc) overnight at $4{ }^{\circ} \mathrm{C}$, washed thoroughly with 


\section{Cellular Physiology Cell Physiol Biochem 2018;48:1480-1491 \\ $\begin{array}{lll}\text { DOI: 10.1159/000492258 } & \text { Ond Biochemistry } 2018 \text { The Author(s). Published by S. Karger AG, Basel } \\ \text { wuww.karger.com/cpb }\end{array}$ \\ Cao et al.: a Heparan Sulfate Cell Mutant Defective in Hepatocyte Growth Factor NK1/ \\ Met Receptor Signaling}

TBST, incubated with horseradish peroxidase-conjugated goat anti-mouse IgG (1:2500 dilution in TBST) for $1 \mathrm{~h}$, and finally visualized using the SuperSignal West Pico Chemiluminescent Substrate from ThermoScientific-Pierce.

Statistical analysis

SPSS for Windows version 10.0.7 was used for statistical analysis. All data are expressed as mean \pm S.E.M. Statistical significance was defined as $\mathrm{P}<0.05$.

\section{Results}

Both CHO-Pos and CHO-Neg cell clones bound to FGFR1C/Fc normally, CHO-Neg cells failed to bind to Met-FC

HGF/GAG binding has been studies extensively for decades; however whether Met can directly bind to cell surface GAGs and if specific GAG structures are responsible for HGF/ Met signaling in vivo remain unclear. 3-0-sulfation is an unique modification that provides HS with specific biological functions [29] and it is known that 3-0-sulfated anticoagulant heparan sulfate and divalent cations are required for FGFR1c binding [14, 15, 30]. We have reported that a CHO cell clone expressing 3-0-sulfotransferase-1 binds to FGFR-Fc. Most importantly, the HS sequences required for FGF or FGFR binding and for FGF/FGFR/HS ternary complex formation are different [31].

Based on such knowledge, we designed a similar strategy (Fig. 2) to isolate Met-Fcbinding positive and negative $\mathrm{CHO}$ mutants [24]. The previously established strategy includes transducing CHOK1 cells with the human HS 3-O-sulfotransferase 1 (3-OST-1) genecontaining recombinant retroviral vector. 3-OST-1 expression gives rise to $\mathrm{CHO}$ cells with the ability to produce anticoagulant HS. A cell line that has three copies of 3-OST-1 is chosen by Southern analysis [24]. Using this unique cell line, we performed chemical mutagenesis and sorted single cell that was FGFR1c-Fc-binding positive and either Met-Fc binding-positive or Met-Fc binding-negative. Such cells were subsequently cloned. The advantage of having three copies of 3-OST-1 is that genes that are responsible for generating HS structures can be

Fig. 2. Scheme for obtaining Met- $\mathrm{Fc}^{+}$and $\mathrm{Met}-\mathrm{Fc}^{-} \mathrm{CHO}$ cell clones. The method employed is similar to the published one [25]. It includes transducing CHOK1 cells with the human HS 3-O-sulfotransferase 1 (3-OST-1) gene-containing recombinant retroviral vector. 3-OST-1 expression gives rise to $\mathrm{CHO}$ cells with the ability to produce anticoagulant HS [24]. A cell line that has three copies of 3-OST-1 is chosen by Southern analysis. After chemical mutagenesis of this cell line, FGFR1c/Fc-binding positive where Met binding-positive or negative mutant cells were FACS-sorted and cloned. The advantage of having three copies of 3-OST-1 is that upstream genes that are responsible for generating HS structures can be sought after chemical mutagenesis without losing 3-OST1. FGFR1c/Fc selection is employed to make certain that the mutant cells still make HS [31] while the cell clones either had or lost the ability to bind to Met-Fc.

Fig. 3. CHO-Pos and CHO-Neg cells bound FGFR1c/ Fc with similar affinity and CHO-Neg cells failed to bind to Met-Fc. Both CHO-Neg and CHO-Pos cells were incubated with either FGFR1c/Fc or Met-Fc, the fluorescence-tagged anti-Fc antibody was used to visualize cell surface bound FGFR1c/Fc or Met-Fc by co-focal microscope at cell cultural conditions.
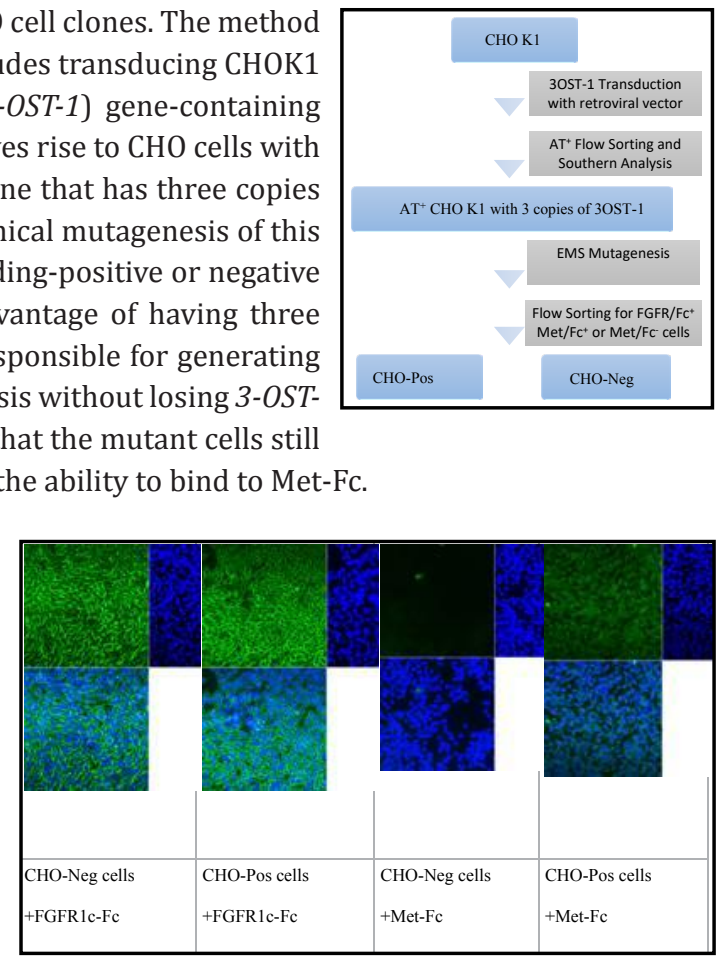


\section{Cellular Physiology Cell Physiol Biochem 2018;48:1480-1491 and Biochemistry \begin{tabular}{c|c} 
DOI: 10.1159/000492258 \\
Published online: July 31, 2018 & $\begin{array}{l}\text { O } 2018 \text { The Author(s). Published by S. Karger AG, Basel } \\
\text { www.karger.com/cpb }\end{array}$ \\
\cline { 2 - 4 }
\end{tabular} Cao et al.: a Heparan Sulfate Cell Mutant Defective in Hepatocyte Growth Factor NK1/ Met Receptor Signaling}

sought after chemical mutagenesis without losing 3-OST-1. FGFR1c-Fc selection is employed to make certain that the mutant cells still make HS [31].

Using this strategy, we successfully isolated and cloned CHO-Pos and CHO-Neg cells. As shown in Fig. 3, when we incubated these two cell lines with either Met-Fc or FGFR1c-Fc followed by probing with anti-Fc antibody, we found that both cell lines bound to FGFR1c-Fc normally, CHO-Pos cells bound to Met-Fc strongly and CHO-Neg cells failed to bind to Met-Fc.

Both Met-Fc binding and HGF/Met/HS or NK1/Met/HS Ternary complex formations on CHO-Pos cells were mainly depended on $H S$

HGF and GAG interactions have been studied extensively for decades. It is well established that both HS and CS-B, i.e. dermatan sulfate, bind to HGF with high affinity $[19,20]$. However, it is still controversial if such interactions promote or inhibit HGF/Met signaling at physiological conditions [32]. To test if Met-Fc binding to CHO-Pos cells were GAG-dependent, we carried out a previously published flow cytometry assays $[23,31]$ where soluble Met-Fc was added to CHO-Pos and CHO-Neg cells with or without co-added HGF or NK1. The cell-bound Met-Fc was detected by FACS using fluorescent labeled anti-Fc antibody. As shown in Fig. 4. CHO-Neg cells had no binding to Met-Fc alone, but co-presence of HGF or NK1 promoted the binding slightly. In contrast, Met-Fc bound to CHO-Pos cells strongly, and this binding was further promoted by either the addition of HGF or NK1. It implied that a Met-Fc/GAG/HGF or NK1 ternary signaling complex was formed on the cell surface.

CHO cells only make two types of GAGs, i.e. HS and CS. To test if HS or CS was responsible for Met-Fc binding and ternary complex formation, we treated the CHO-Pos and CHO-Neg cells with heparitinase and chondroitinase $\mathrm{ABC}$, respectively. Heparitinase treatment totally abolished the binding of Met-Fc to the cell surface and destroyed the ternary complex, while chondroitinase $\mathrm{ABC}$ treatment reduced MetFc cell surface binding but had not effect on the ternary complex. These observations indicated that Met-Fc alone could bind to

Table 1. CHO-Pos and CHO-Neg cells were untreated or treated with heparitinase or chondroitinase $\mathrm{ABC}$, respectively. Soluble Met-Fc was added to the untreated or treated CHO-Pos and CHO-Neg cells with or without co-added HGF or NK1. The fluorescent intensity (au) of cellbound Met-Fc was detected by FACS using fluorescent labeled anti-Fc antibody.

\begin{tabular}{|c|c|c|c|c|c|}
\hline & & \multicolumn{2}{|l|}{ CHO-Neg } & \multicolumn{2}{|l|}{ CHO-Pos } \\
\hline & & Fluorescent intensity & SD & Fluorescent intensity (au) & SD \\
\hline \multirow{4}{*}{ Untreated } & Met-Fc & 4.00 & \pm 0.23 & 73.53 & \pm 8.23 \\
\hline & Met-Fc + HGF & 6.67 & \pm 0.44 & 3250.00 & \pm 102.50 \\
\hline & Met-Fc +NK1 & 5.33 & \pm 0.33 & 2125.00 & \pm 60.22 \\
\hline & Met-Fc & 3.33 & \pm 0.16 & 3.31 & \pm 0.25 \\
\hline \multirow{2}{*}{ + Heparinlyase } & Met-Fc + HGF & 4.67 & \pm 0.11 & 4.62 & \pm 0.17 \\
\hline & Met-Fc +NK1 & 6.00 & \pm 0.38 & 6.05 & \pm 0.46 \\
\hline \multirow{3}{*}{ +Chondroitinase $\mathrm{ABC}$} & Met-Fc & 4.10 & \pm 0.28 & 10.00 & \pm 1.56 \\
\hline & Met-Fc + HGF & 3.34 & \pm 0.17 & 1000.00 & \pm 42.33 \\
\hline & Met-Fc +NK1 & 4.66 & \pm 0.25 & 2588.24 & \pm 70.58 \\
\hline
\end{tabular}

Fig. 4. HS was required for HGF or NK1/Met-Fc/ GAG Ternary complex formation on $\mathrm{CHO}$ cells assayed by flow cytometry. Both CHO-Neg (left panel) and CHO-Pos (right panel) cells were sequentially sorted with Met-Fc, HGF and MetFc, and NK1 and Met-Fc. Ten thousand events were counted for each sample, the fluorescencetagged anti-Fc antibody was used to monitor cell surface bound Met-Fc. Upper panal, without enzyme treatment; Middle panel, with heparinase treatment. Lower panel, with chondroitinase

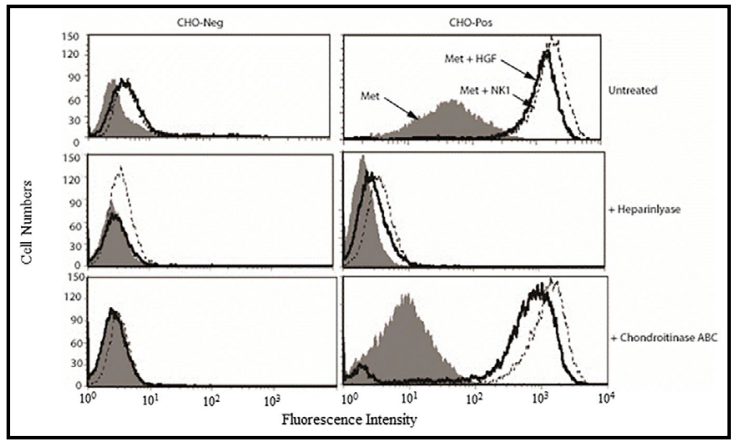
ABC treatment. The data in the three panels are a representative of three independent experiments; the statistical fluorescent intensity data are summarized in table 1. 


\section{Cellular Physiology Cell Physiol Biochem 2018;48:1480-1491 \begin{tabular}{ll|l} 
and Biochemistry Published online: July 31, 2018 & $\begin{array}{l}\text { (c) } 2018 \text { The Author(s). Published by S. Karger AG, Basel } \\
\text { www.karger.com/cpb }\end{array}$
\end{tabular} \\ Cao et al.: a Heparan Sulfate Cell Mutant Defective in Hepatocyte Growth Factor NK1/ Met Receptor Signaling}

both HS and CS on the cell surface, while HS was absolutely required for the ternary complex (Met-Fc/HS/HGF or Met-Fc/HS/NK1) formations.

\section{CHO-Neg cells made less HS than that of CHO-Pos cells}

We next addressed why CHO-Neg cells failed to bind to Met-Fc (Fig. 3). It is known the GAG composition, chain length, and the fine structures would ultimately determine whether the growth factor or their receptors could interact with cell surface GAGs. To test if CHONeg cells had changed GAG composition, i.e. HS\% vs. CS\%, we isolated GAGs in cell culture media, GAGs at cell surface by collecting trypsin released cell surface component and the rest of GAGs from the cells from both $\mathrm{CHO}-\mathrm{Pos}$ and $\mathrm{CHO}-\mathrm{Neg}$ cells. The repeating disaccharides in HS are glucosamine (GlcN) and uronic acid and in CS are galactosamine and uronic acid, respectively. Thus, GlcN represents HS and GalN represents CS.

The amount of GlcN and GalN in the isolated GAGs were quantified by a published reverse phase HPLC method [26]. The analytical results of GAG compositions, i.e. HS\% vs. CS\%, are summarized in Fig. 5. The data showed that HS\% from CHO-Neg cell-associated, cell surface, and medium GAGs were reduced by $10.66 \%, 7.77 \%$, and $7.87 \%$, respectively, compared to that of CHO-Pos cells (Fig. 5), suggesting CHO-Neg might be associated with defects in HS fine structures.

HS chain of CHO-Neg cells was different in charge density, chain length, and disaccharide compositions compared to that CHO-Pos cells

It has been established the HS and CS chains from either CHOK1 [28] or CHOK1.5 [24, 25] (the cell clone expressing three copied of 3-OST1) can be resolved HPLC anion-exchange analysis where HS is eluted from $0.28-0.52 \mathrm{M}$ of $\mathrm{NaCl}$ and $\mathrm{CS}$ is eluted from $0.52-0.62$ $\mathrm{M}$ of $\mathrm{NaCl}$. To test if the ${ }^{35} \mathrm{~S}$-sulfate labeled GAGs form both CHO-Pos and CHO-Neg cells had changed HS or CS charge density, we performed the HPLC anion-exchange analysis (Fig. 6). The data showed that CSs produced by the both cells were eluted with the identical $\mathrm{NaCl}$ gradient whereas the HS of CHO-Neg cells was eluted slightly ahead that of CHO-Pos cells, suggesting HS of CHO-Neg cells was less charged.

We next tested the HS chain length by gel filtration HPLC (Fig. 7). Interestingly, ${ }^{35}$-sulfate labeled HS from CHO-Pos cells was eluted slightly ahead of that of CHONeg cells, indicating the HS made by CHO-Neg cells had shorter HS chain length.

Both anion exchange and gel filtration HPLC analysis indicated that overall HS structures of the CHO-Neg cells might not be the same as that of $\mathrm{CHO}-$

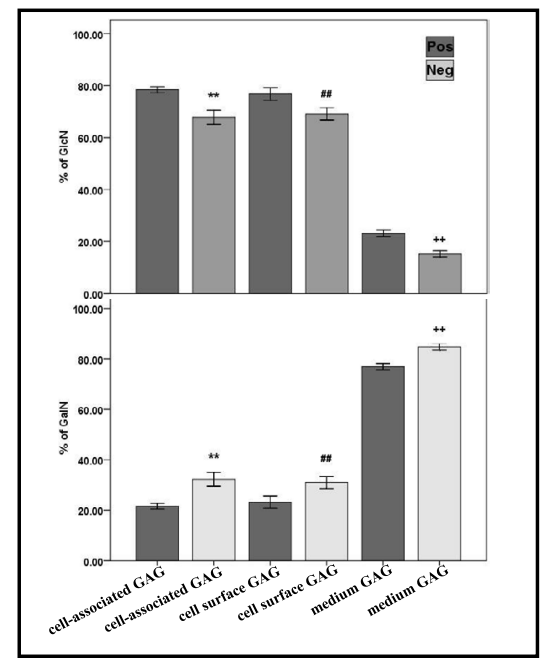

Fig. 5. Quantification of glucosamine (GlcN) and galactosamine (GalN) content of GAGs isolated from the cell culture media, cell surface, and cell-associated CHO-Pos and CHONeg cells. GAGs were isolated (see "Methods"). The purified GAGs were then hydrolyzed into monosaccharides. GlcN and GalN were quantified based on our published method [26]. The data were presented as mean \pm S.D. $(n=$ 4). Significance: $P<0.05$ where all the $p$ values for ${ }^{* *}, \# \#$, and ++ were less than 0.0001 .

Fig. 6. GAGs from CHO-Neg cells were slightly less sulfated that that of CHO-Pos cells based on HPLC anion-exchange chromatography analysis. ${ }^{35} \mathrm{~S}$-sulfate labeled GAG chains from $\mathrm{CHO}$-Pos and $\mathrm{CHO}-\mathrm{Neg}$ cells were isolated (see "Methods") and analyzed by HPLC anionexchange chromatography (see "Methods"). Blue line: GAGs from CHO-Pos cells; Red line: GAGs from CHO-Neg cells; The broken line represents the $\mathrm{NaCl}$ concentration gradient. Each HPLC run was repeated twice and identical HPLC profiles were obtained.

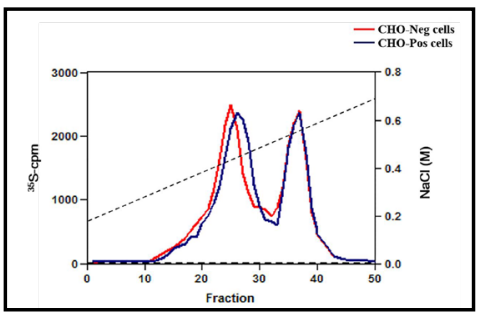




\section{Cellular Physiology Cell Physiol Biochem 2018;48:1480-1491 \begin{tabular}{ll|l} 
and BiOChemistry Published online: July 31, 2018 & $\begin{array}{l}\text { (c) 2018 The Author(s). Published by S. Karger AG, Basel } \\
\text { www.karger.com/cpb }\end{array}$ \\
\hline
\end{tabular} \\ Cao et al.: a Heparan Sulfate Cell Mutant Defective in Hepatocyte Growth Factor NK1/ \\ Met Receptor Signaling}

Fig. 7. HS from CHO-Neg cells had shorter chain length than that of CHO-Pos cells based on HPLC gel filtration chromatography. HS chains was obtained after chondroitinase $\mathrm{ABC}$ treatment of ${ }^{35} \mathrm{~S}$-sulfate labeled GAG chains from both CHO-Pos and CHO-Neg cells (see "Methods") and analyzed by HPLC Gel filtration chromatography (see "Methods"). Blue line: HS from CHO-Pos cells; Red line: HS from CHO-Neg cells. Each HPLC run was repeated twice and identical HPLC profiles were obtained.

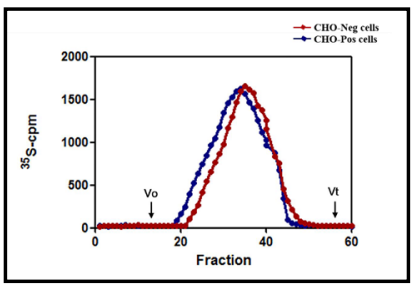

Pos cells. HS consists of repeating uronic acid (glucuronic acid [GlcA] or iduronic acid [IdoA]) and GlcN disaccharide units where the sulfates could be added to the 2-position of uronic acid and N-, 3-, and 6-position of $\mathrm{GlcN}$, which generates a variety of the disaccharides with variably sulfated or nonsulfated GlcA/IdoA and GlcN residues. Thus far, disaccharide composition is the conventional way to characterize HS structure. Using the previously established method of heparitinase digestion followed by HPLC coupled MS analysis [33], the

Table 2. Disaccharide composition of HS from CHOPos and CHO-Neg cells. GAGs from CHO-Pos and CHO-Neg cells were isolated. After removing CS by chondroitinase $\mathrm{ABC}$ from the GAGs, the purified HS was digested with a mixture of heparitinases. The resulting disaccharides were further resolved by HPLC and identified by MS analysis [33]. In three independent experiments, the values varied by $20 \%$ of those shown. $\triangle \mathrm{UA}$ : unsaturated uronic acid generated by heparitinase digestion

\begin{tabular}{lcc}
\hline Name & CHO-Pos & CHO-Neg \\
\hline UUA-GlcNS & $30 \%$ & $29 \%$ \\
UUA-GlcNAc & $7 \%$ & $10 \%$ \\
UUA-GlcNS6S & $9 \%$ & $7 \%$ \\
DUA2S-GlcNS & $20 \%$ & $23 \%$ \\
DUA2S-GlcNS6S & $34 \%$ & $31 \%$ \\
\hline
\end{tabular}
HS disaccharide compositions were compared between CHO-Pos and CHO-Neg cells. The data are summarized in Table 2 . In three independent experiments, we found that the two disaccharides containing 6-0-sulfates in HS of CHO-Neg cells, i.e. $\triangle \mathrm{UA}$-GlcNS6S and $\triangle \mathrm{UA2S}$-GlcNS6S, were consistently 2-3\% lower than that in HS of CHO-Pos cells, which indicated that the CHO-Neg cells had a defect in 6-0-sulfate-containing disaccharides.

MAPK phosphorylation was defective in CHO-Neg cells when induced with NK1

It is known that CHO cells express endogenous Met [11]. HGF or Nk1 bind and activate the Met transmembrane tyrosine kinase. Upon ligand binding, Met activates phosphatidylinositol 3-kinase (PI3K) and mitogen-activated protein kinase (MAPK) through the Gab1/Grb2-SOSRas pathway [19, 34]. The question we asked was how the Met-Fc binding deficiency in CHO-Neg cells due to reduced 6-O-sulfation and shorter HS chains on the cell surface impacted the HGF/Met or NK1/Met signaling at the cellular level. To this end, we incubated CHO-Neg and CHO-Pos cells with either full length HGF or its truncated form NK1 for $10 \mathrm{~min}$ in serum-free media, then lysed the cells, directly detect the expression levels of phosphorylated and non-phosphorylated MAPK by Western analysis. Even though HGF and NK1 were equal at forming a ternary complex with Met-Fc and GAGs at cell surface (Fig. 4) and both cell lines expressed the same levels of non-phosphorylated MAPKs, NK1 was defective in MAPK phosphorylation only with CHO-Neg cells. As shown in Fig. 8, HGF and NK1 display comparable levels of Phosphor-p42-MAPK and Phosphor-p42-MAPK in CHOPos cells, while HGF had normal level of Phosphor-p42-MAPK and Phosphor-p42-MAPK in CHO-Neg cells, NK1 had only control level of Phosphor-p42-MAPK and Phosphor-p42-MAPK in CHO-Neg cells. Thus, the HS structural defects in CHO-Pos cells led to specific NK1/Met signaling defect. 


\section{Cellular Physiology Cell Physiol Biochem 2018;48:1480-1491

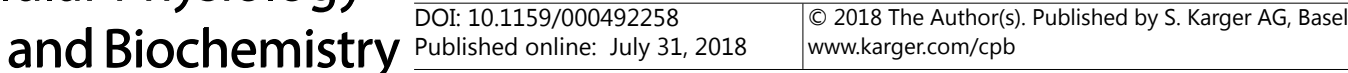 \\ Cao et al.: a Heparan Sulfate Cell Mutant Defective in Hepatocyte Growth Factor NK1/ \\ Met Receptor Signaling}

Fig. 8. MAPK phosphorylation was defective in CHONeg cells when induced with NK1 evidenced by Western analysis. CHO-Neg and CHO-Pos cells were seeded at a confluent density into a 6-well plate in $2 \mathrm{ml}$ of Ham's F-12, 10\% (v/v) FBS, and serum-starved overnight before treatment with HGF or NK1 $(10 \mathrm{ng} / \mathrm{mL}$ each) for $10 \mathrm{~min}$. Cells were then lysed in $0.1 \mathrm{~mL}$ of non-reducing Laemmli SDS-sample buffer. Equivalent amounts of protein samples

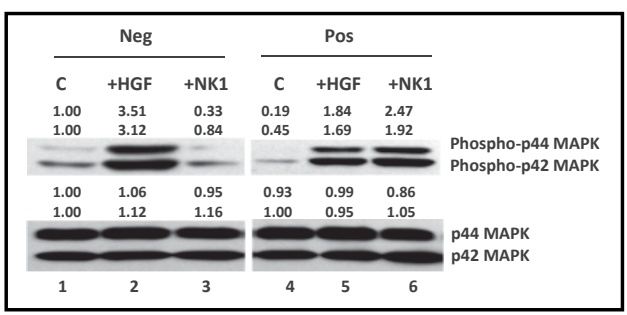
were subjected to SDS-PAGE on a $10 \%$ acrylamide gel and then blotted onto nitrous cellular membrane. Blots were blocked and then probed with a mouse monoclonal antibody against phosphor-p42/44 MAPK or p42/44 MAPK, followed by incubating with horseradish peroxidase conjugated goat anti-mouse IgG and visualized. The numbers underneath the blots represent relative band intensity (the means of three independent experiments) that was measured by Image J software and normalized to the corresponding control band of Neg (defined the intensity as 1 ). The experiments were repeated three times with all relative band intensities within $15 \%$ of the means.

\section{Discussion}

It is reported that a CHO cell mutant (CHO 745 cells) defective in both HS and CS biosynthesis is failed to initiate both NK1- and HGF-induced Met signaling [11] and HGF binds to both HS and CS-B [20]. In current study, we found for the first time that Met-Fc interacted with cell surface GAGs. Moreover, the unique CHO mutant, $\mathrm{CHO}-\mathrm{Neg}$, with shorter HS chain length and reduced 6-O-sulfate-containing HS disaccharides, was defective not only in Met-Fc binding but also in NK1- not HGF-induced MAPK phosphorylation. Thus, CHO-Neg cells were different from that of CHO745 cells in HGF/Met signaling and this cell line was provided with a unique tool to empathize the important roles of fine HS structures played in regulating HGF/Met signaling.

We have previously demonstrated that the HS binding sequences for FGF, FGFR, and FGF plus FGFR are different [31]. We proposed that the HS sequence for FGF/HS/FGFR ternary complex formation and signaling might not be the HS sequences for either FGF or FGFR binding [31]. Studies of HS interaction with HGF have shown that a tetrasaccharide is the minimal active species. There is also evidence indicating that trisaccharides may be capable of interacting with HGF. Previous studies suggested that neither N-sulfates nor 2-O-sulfates are specifically required for HS binding to HGF, but that 6-0-sulfation might be the most important for the binding [20]. In addition, heparin and CS-B interact with HGF [20]. The data shown in Fig. 4 indicated that CS in CHO-Neg might contribute to Met-Fc and cell surface GAG binding since chondroitinase $\mathrm{ABC}$ reduced the Met-Fc binding significantly. However, HS was required for the cell surface HGF/Met-Fc or NK1/Met-Fc binding evidenced by a total abolishing such binding after heparitinase digestion (Fig. 4). These data also supported the notion that the Met-Fc binding GAG sequence might be not the same as the HS sequences that were used for HGF/HS/Met ternary complex formation.

Indeed, several studies reported that both HGF and GAGs are directly involved in dimerization of $\operatorname{HGF}[10,11,35]$ or HGF/GAG/Met ternary complex formation $[19,21,36$, 37]. More recent work has indicated that overall sulfate density is more critical than strict sulfate positioning. However, most of these findings about the role of GAGs in regulating Met/HGF signaling are based on the studies using exogenous heparin, CS or DS, studying GAGs directly in a cell-based model would give much clear and accurate acknowledgement about GAG regulation of Met signal pathway.

It was unclear why the CHO-Neg cells were only defective in NK1- but not HGF-induced induced Met signaling (Fig. 8). Based on the domain structure shown in Fig. 1, we speculated that the extra domain structures that are only present in HGF might make HS structure requirement for Met signaling less demanding. Indeed, after reviewing the considerable amount of published work [36], Kemp et al. proposed that the role of HS in forming the HGF/ Met signaling complex is required to be further defined. GAGs that facilitate HGF to achieve 


\section{Cellular Physiology Cell Physiol Biochem 2018;48:1480-1491 and Biochemistry Published online:-July 31, $2018 \quad \begin{aligned} & \text { DOI 10159/2018 The Author(s). Published by S. Karger AG, Basel } \\ & \text { www.karger.com/cpb }\end{aligned}$ \\ Cao et al.: a Heparan Sulfate Cell Mutant Defective in Hepatocyte Growth Factor NK1/ Met Receptor Signaling}

Met dimerization and to trigger various signaling pathways vary in a cell-dependent manner, which may reflect the facts that GAGs made by different cell types are different. The function of GAGs might include but not limited to stabilization of the dimeric HGF, to protect the HGF or its isoforms from protease degradation, to serve as a repository for HGF or its isoforms, to form the active signaling HGF/Met ternary complex, or a combination of all above, and further studies are clearly needed to ascertain specific GAG structures in regulating the Met signaling system both in vivo and in vitro [9-12, 19-21, 32, 35-37].

\section{Conclusion}

This study demonstrated that soluble Met-Fc bound to cell surface HS at physiological conditions and a Met/HGF/NK1/HS ternary signaling complex might be involved in Met signaling. Shorter HS chains and reduced 6-0-sulfation might be responsible for reduced Met-Fc binding and the diminished NK1-initiated signaling in the CHO-Neg cells. Such knowledge should be useful in developing GAG-based compounds that regulate HGF/Met signaling.

\section{Abbreviations}

GAGs (glycosaminoglycans); HS (heparan sulfate); CS (chondroitin sulfate); GlcA (glucuronic acid); IdoA (iduronic acid); GlcNAc ( $N$-acetylglucosamine); GlcNS ( $N$-sulfated glucosamine); GlcN (glucosamine); GalN (galactosamine); $\Delta \mathrm{UA}$ (unsaturated uronic acid); $2 \mathrm{~S}$ (2-O-sulfate); 6S (6-O-sulfate); $\mathrm{NS}$ ( $\mathrm{N}$-sulfate); $\mathrm{CHO}$ (Chinese hamster ovary); Met (hepatocyte growth factor Met receptor); HGF (hepatocyte growth factor); NK1 (the N- and K1 domain of HGF); CHO-Neg (Met-Fc recombinant protein-binding negative CHO cells); CHO-Pos (Met-Fc recombinant protein-binding positive $\mathrm{CHO}$ cells); HPLC (, high performance liquid chromatography); OPA (o-phthaldialdehyde); 3MPA (3-mercaptopropionic acid); TBS (Trisbuffered saline); MAPK (mitogen activated protein kinase).

\section{Acknowledgements}

We thank Dr. Donald P. Bottaro of National Institutes of Health for providing us with NK1 and Dr. Jeffrey D. Esko of UCSD for providing us with CHOK1 cell line.

This research was supported by Natural Science Foundation of China (Grant No. 81672585); Key Technology Fund of Shandong Province (Grant 2016ZDJS07A07); the "Double First-Class" fund of Shandong Province; and National Institutes of Health Grant R01GM069968 to LZ.

JP and LZ designed the experiments. TC, JP, XL, YL, YJ, YC, and QZ performed the experiments. TC, JP, WJ, HW, ZT, and LZ analyzed data. TC, JP, and LZ wrote the manuscript. All authors read and approved the final manuscript.

There was no research involving human or animal subjects in the study.

All data supporting the findings in this study are included within the manuscript.

\section{Disclosure Statement}

The authors declare that they have no competing interests. 


\section{Cellular Physiology Cell Physiol Biochem 2018;48:1480-1491

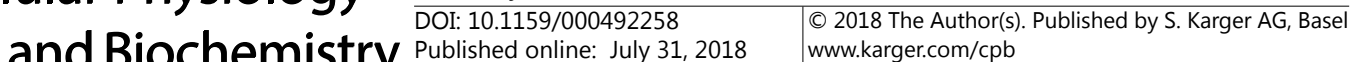 and Biochemistry Published online: July $\frac{\text { Cao et al:: a Heparan Sulfate Cell Mutant Defective in Hepatocyte Growth Factor NK1/ }}{\text { Call }}$ Met Receptor Signaling}

\section{References}

1 Szturz P, Raymond E, Abitbol C, Albert S, de Gramont A, Faivre S: Understanding c-MET signalling in squamous cell carcinoma of the head \& neck. Crit Rev Oncol Hematol 2017;111:39-51.

-2 Lam BQ Dai L, Qin Z: The role of HGF/c-MET signaling pathway in lymphoma. J Hematol Oncol 2016;9:135.

-3 Marano L, Chiari R, Fabozzi A, De Vita F, Boccardi V, Roviello G, Petrioli R, Marrelli D, Roviello F, Patriti A: C-Met targeting in advanced gastric cancer: An open challenge. Cancer Lett 2015;365:30-36.

4 Ho-Yen CM, Jones JL, Kermorgant S: The clinical and functional significance of c-Met in breast cancer: A review. Breast Cancer Res 2015;17:52.

5 Maroun CR, Rowlands T: The Met receptor tyrosine kinase: A key player in oncogenesis and drug resistance. Pharmacol Ther 2014;142:316-338.

6 Gelsomino F, Facchinetti F, Haspinger ER, Garassino MC, Trusolino L, De Braud F, Tiseo M: Targeting the MET gene for the treatment of non-small-cell lung cancer. Crit Rev Oncol Hematol 2014;89:284-299.

-7 Cecchi F, Rabe DC, Bottaro DP: Targeting the HGF/Met signaling pathway in cancer therapy. Expert Opin Ther Targets 2012;16:553-572.

-8 Cui JJ: Targeting receptor tyrosine kinase MET in cancer: Small molecule inhibitors and clinical progress. J Med Chem 2014;57:4427-4453.

-9 van der Voort R, Taher TE, Wielenga VJ, Spaargaren M, Prevo R, Smit L, David G, Hartmann G, Gherardi E, Pals ST: Heparan sulfate-modified CD44 promotes hepatocyte growth factor/scatter factor-induced signal transduction through the receptor tyrosine kinase c-Met. J Biol Chem 1999;274:6499-6506.

10 Schwall RH, Chang LY, Godowski PJ, Kahn DW, Hillan KJ, Bauer KD, Zioncheck TF: Heparin induces dimerization and confers proliferative activity onto the hepatocyte growth factor antagonists NK1 and NK2 J Cell Biol 1996;133:709-718.

11 Sakata H, Stahl SJ, Taylor WG, Rosenberg JM, Sakaguchi K, Wingfield PT, Rubin JS: Heparin binding and oligomerization of hepatocyte growth factor/scatter factor isoforms. Heparan sulfate glycosaminoglycan requirement for Met binding and signaling. J Biol Chem 1997;272:9457-9463.

-12 Garner OB, Bush KT, Nigam KB, Yamaguchi Y, Xu D, Esko JD, Nigam SK: Stage-dependent regulation of mammary ductal branching by heparan sulfate and HGF-cMet signaling. Dev Biol 2011;355:394-403.

13 Zhang L: Glycosaminoglycan (GAG) biosynthesis and GAG-binding proteins. Prog Mol Biol Transl Sci 2010;93:1-17.

14 Kan M, Wang F, Xu J, Crabb JW, Hou J, McKeehan WL: An essential heparin-binding domain in the fibroblast growth factor receptor kinase. Science 1993;259:1918-1921.

15 Kan M, Wang F, To B, Gabriel JL, McKeehan WL: Divalent cations and heparin/heparan sulfate cooperate to control assembly and activity of the fibroblast growth factor receptor complex. J Biol Chem 1996;271:2614326148.

16 Powell AK, Fernig DG, Turnbull JE: Fibroblast growth factor receptors 1 and 2 interact differently with heparin/heparan sulfate. Implications for dynamic assembly of a ternary signaling complex. J Biol Chem 2002;277:28554-28563.

17 Schlessinger J, Plotnikov AN, Ibrahimi OA, Eliseenkova AV, Yeh BK, Yayon A, Linhardt RJ, Mohammadi M: Crystal structure of a ternary FGF-FGFR-heparin complex reveals a dual role for heparin in FGFR binding and dimerization. Mol Cell 2000;6:743-750.

-18 Chirgadze DY, Hepple JP, Zhou H, Byrd RA, Blundell TL, Gherardi E: Crystal structure of the NK1 fragment of HGF/SF suggests a novel mode for growth factor dimerization and receptor binding. Nat Struct Biol 1999;6:72-79.

19 Rubin JS, Day RM, Breckenridge D, Atabey N, Taylor WG, Stahl SJ, Wingfield PT, Kaufman JD, Schwall R, Bottaro DP: Dissociation of heparan sulfate and receptor binding domains of hepatocyte growth factor reveals that heparan sulfate-c-met interaction facilitates signaling. J Biol Chem 2001;276:32977-32983.

20 Lyon M, Deakin JA, Lietha D, Gherardi E, Gallagher JT: The interactions of hepatocyte growth factor/scatter factor and its NK1 and NK2 variants with glycosaminoglycans using a modified gel mobility shift assay. Elucidation of the minimal size of binding and activatory oligosaccharides. J Biol Chem 2004;279:4356043567.

-21 Gherardi E, Youles ME, Miguel RN, Blundell TL, Iamele L, Gough J, Bandyopadhyay A, Hartmann G, Butler PJ: Functional map and domain structure of MET, the product of the c-met protooncogene and receptor for hepatocyte growth factor/scatter factor. P Natl Acad Sci USA 2003;100:12039-12044. 


\section{Cellular Physiology Cell Physiol Biochem 2018;48:1480-1491

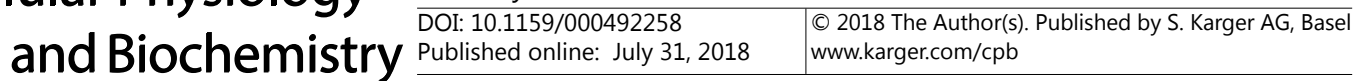 \\ Cao et al.: a Heparan Sulfate Cell Mutant Defective in Hepatocyte Growth Factor NK1/ Met Receptor Signaling}

22 Esko JD, Stanley P: Glycosylation Mutants of Cultured Cells. In: Essentials of Glycobiology. 2nd edn. Edited by Varki A, Cummings RD, Esko JD, Freeze HH, Stanley P, Bertozzi CR, Hart GW, Etzler ME. Cold Spring Harbor (NY); 2009.

23 Zhang L, Lawrence R, Frazier BA, Esko JD: CHO glycosylation mutants: Proteoglycans. Methods Enzymol 2006;416:205-221.

-24 Zhang L, Beeler DL, Lawrence R, Lech M, Liu J, Davis JC, Shriver Z, Sasisekharan R, Rosenberg RD: 6-0-sulfotransferase-1 represents a critical enzyme in the anticoagulant heparan sulfate biosynthetic pathway. J Biol Chem 2001;276:42311-42321.

-25 Zhang L, Lawrence R, Schwartz JJ, Bai X, Wei G, Esko JD, Rosenberg RD: The effect of precursor structures on the action of glucosaminyl 3-0-sulfotransferase-1 and the biosynthesis of anticoagulant heparan sulfate. J Biol Chem 2001;276:28806-28813.

-26 Studelska DR, Giljum K, McDowell LM, Zhang L: Quantification of glycosaminoglycans by reversed-phase HPLC separation of fluorescent isoindole derivatives. Glycobiology 2006;16:65-72.

27 Zhang L, Esko JD: Amino acid determinants that drive heparan sulfate assembly in a proteoglycan. J Biol Chem 1994;269:19295-19299.

28 Bai X, Esko JD: An animal cell mutant defective in heparan sulfate hexuronic acid 2-0-sulfation. J Biol Chem 1996; 271:17711-17717.

29 Thacker BE, Xu D, Lawrence R, Esko JD: Heparan sulfate 3-O-sulfation: A rare modification in search of a function. Matrix Biol 2014; 35:60-72.

-30 McKeehan WL, Wu X, Kan M: Requirement for anticoagulant heparan sulfate in the fibroblast growth factor receptor complex. J Biol Chem 1999; 274:21511-21514.

31 Wu ZL, Zhang L, Yabe T, Kuberan B, Beeler DL, Love A, Rosenberg RD: The involvement of heparan sulfate (HS) in FGF1/HS/FGFR1 signaling complex. J Biol Chem 2003; 278:17121-17129.

-32 Hartmann G, Prospero T, Brinkmann V, Ozcelik C, Winter G, Hepple J, Batley S, Bladt F, Sachs M, Birchmeier C, Birchmeier W, Gherardi E: Engineered mutants of HGF/SF with reduced binding to heparan sulphate proteoglycans, decreased clearance and enhanced activity in vivo. Curr Biol 1998;8:125-134.

-33 Lu H, McDowell LM, Studelska DR, Zhang L: Glycosaminoglycans in human and bovine serum: Detection of Twenty-Four heparan sulfate and chondroitin sulfate motifs including a novel sialic acid-modified chondroitin sulfate linkage hexasaccharide. Glycobiol Insights 2010;2010:13-28.

-34 Day RM, Cioce V, Breckenridge D, Castagnino P, Bottaro DP: Differential signaling by alternative HGF isoforms through c-Met: Activation of both MAP kinase and PI 3-kinase pathways is insufficient for mitogenesis. Oncogene 1999;18:3399-3406.

-35 Zioncheck TF, Richardson L, Liu J, Chang L, King KL, Bennett GL, Fugedi P, Chamow SM, Schwall RH, Stack RJ: Sulfated oligosaccharides promote hepatocyte growth factor association and govern its mitogenic activity. J Biol Chem 1995;270:16871-16878.

-36 Lietha D, Chirgadze DY, Mulloy B, Blundell TL, Gherardi E: Crystal structures of NK1-heparin complexes reveal the basis for NK1 activity and enable engineering of potent agonists of the MET receptor. Embo J 2001;20:5543-5555.

37 Kemp LE, Mulloy B, Gherardi E: Signalling by HGF/SF and Met: The role of heparan sulphate co-receptors. Biochem Soc Trans 2006;34:414-417. 